\title{
Universal Simplest possible PLC using Personal Computer
}

\author{
B.K.Rana \\ Electrical Engg., \\ VSSUT, Sambalpur Orissa , India \\ bkrana@ rediffmail.com
}

\begin{abstract}
Need of industrial automation and control is not closed yet. PLC, the programmable logic controller as available in 2009 with all standardized possible features, discussed here concisely. This work on PLC gives a simplest form built in any computer hardware and software for immediate flexible need of the product in a small environment any number inputs and output logic permitted by a computer. At first, the product logic is implemented using simple available computer using a PCIMCIA card having 8255 parallel I/O device, RS232 etc. software like Java, C, C++, and Visual Basic. Further work continuing with all coming generations and variation in the mentioned technology. Expert engineer having these skills may fabricate a small operating PLC within one month. This is a view of preliminary work. Further up gradation of this work comes in term of Visual programming tool (computer aided design) and also universal make in terms of all operating system and computer available in the world. Sensors and module for data to logic conversion is not emphasized in this work. Connectivity has to be as per standard. Immediate use of this work as an education technology kit. The work in this huge technology area should not be accused because this is need in some way.
\end{abstract}

Keywords- PLC, prototype, Java, Visual Basic, education technology

\section{INTRODUCTION}

Everybody will agree that there is no need to describe the 25 years of technology and concepts of PLC. It is surveyed and many small key points are discussed towards another offshoot of this technology. The objective to develop a low cost trainer or education technology kit is realized. This work further can be extended to a small PLC prototype. As a trainer it should be safe, low cost, programming flexibility, multi input and multi output system. Logic system at front end computer (display, editor, logic evaluation), universal communication for commercial PLCs are the work done here. Universal make for these components are considered so that it works with any computer system. At present the work is carried in Personal computer. Java being a universally portable front end environment is considered here.

\section{PRESENT PLC FEATURES}

\section{A. A. Manufacturing Companies}

It is manufactured by companies like Brands - Lab-Volt, Allen-Bradley, Rockwell Automation, Allen-Bradley, Panel View Operator Terminals, Aromatic PLC, Automation Direct, Cutler Hammer, GE Series, Exor, IDEC, Koyo, Maple Systems, Mitsubishi, Madison, Omron PLC, Reliance Automate, Siemens, Square D, Texas Instruments, Toshiba.

\section{B. Use of PLC at this stage}

Precisely PLC is used in industrial environment for area like, Equipment status Process Control Chemical Processing, Equipment Interlocks, Machine protection, Smoke detection, Gas monitoring, Envelope monitoring, Personal monitoring, System setup and device monitoring, Bench marks, maximum $\mathrm{I} / \mathrm{O}$ ports etc.

\section{Lingering concerns about PLC}

- Security and robustness. Failure in any part of the computer system such as crash, rebooting, disk problem gives inaccuracy to plant output functions and hence uncertainty in real plant dynamics.

- $\quad$ PLC in networked computers. Operating PLC from now days generic Ethernet based computer network is one of studies going now.

\section{Standards for PLC}

Contrary to proprietary or closed design open system design is carried out 1980 onward. This gives control over technology and flexibility to customer.

- International engineering consumerism IEC 61131-3 standardize ladder logic ( graphical ), function block diagram (graphical ), structured text ( textual ) and instruction set ( textual) . IEC 61850 process bus interface.

- In detail IEC 61131-3 is given as overview, requirement and test procedures, data type and programming, user guide lines, communication and fuzzy control. 
- Organize programs for sequential and parallel control processing.

\section{E. Fundamentals of PLC software}

The list of software elements in PLC are method of representing logic, instruction, code, graphical presentation ( functional logic diagram and ladder logic ) Fundamental ladder logic instruction set comparison of different manufacturers, processor, memory and instruction code, Real Time ability particularly real time clock.

\section{F. Fundamentals of PLC hardware}

The list of hardware elements in PLC are block diagram of typical PLC, PLC - processor module memory organization, Input /Output section: module types, Power supply .

\section{CONCEPT OF THIS PLC}

This work of PLC, after a long evolution, aims at producing an education technology kit at first with very minimum cost. Also this work in later version will produce cream of application of Software Engineering in industrial automation. The simple possible PLC work is done with present software available for present personal computers.

The cost of producing this simple work comprises of a personal computer, Visual Basic, Java (free), C++, Printer \& com port cable etc. may be $\$ 5000.00$. Excessive optimization is done to make this PLC as simplest possible.

\section{PRELIMINARY DESIGN}

\section{A. Software Engineering Requirements}

Since this product logic is based on matured software languages and tools for visual concepts no more to bother for this. For example Java being a Object Oriented Programming Language nothing mean in terms of software engineering for this project. Communication and Device driver part requires some special Software Engineering for which plenty of international works are available in IEEE [2, 3].

\section{B. B. Connection in this PLC}

Parallel or Serial port driver for PC to PLC connection may be built with Java front end and Java Native-Win32 driver. Further work is under progress. Figure 1 gives the software architecture stack for communication module. User interface of the communication stack can be high level language like java with native interface. Device driver layer may be developed with $\mathrm{C}$ or $\mathrm{C}++$. This communication stack is built with the concept of OSI (open system interconnection) [4].
Table 1 lists the possible use of communication devices like Intel 8255 (parallel device), Intel 8251(serial device) and Personal Computer's serial communication port like COM1 and COM2. Communication hardware module may be designed with standard PC bus interface specification like PCMIMCIA.

\section{Report generation}

Report of activity and data may be generated in this experimental PLC model using Microsoft Excel for Visual Basic front end design tool, simple text file is first for all universal form of design. In windows environment simple database like MS Access is sufficient and XML may be a universal form.

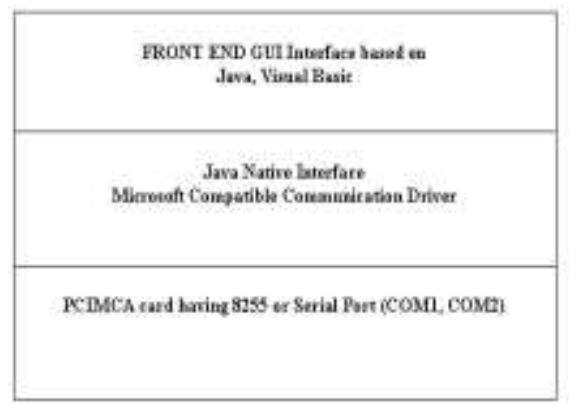

Figure 1. Present Version of communication stack and interface

\section{Theoretical Interface}

This section depicts what should be the logic of designing the human machine interface for the small effective PLC. This can be designed using Java, Visual Basic, Motif, C++ etc. The graphical user interface components depicted in this design section are standard components like Frame, Command Button, Check Box, Image etc. Figure 2 gives theoretical interface for this small PLC.

The "Plant Control < number $>$ "is the container for the ladder diagram. Any number (N) of Plant Control can be run simultaneously. The ladder diagram is designed using standard drawing software tool like Microsoft Word and the cut with image file like (jpeg, gif, bmp etc.). It can be selected to run or disable from running by the left check box.

For each plant control, the output function should be written in the used programming language. Optimization of this function by Karnaugh map be used. 
TABLE I : AVAILABLE COMMUNICATION STANDARD AND MECHANISM

\begin{tabular}{|c|c|c|c|}
\hline $\begin{array}{c}\text { Communication } \\
\text { device / standard }\end{array}$ & Type & PC Interface & Remark \\
\hline 8255 & Intel parallel port device & PCIMCIA card & $\begin{array}{c}\text { Data Link Layer } \\
\text { Layed Architecture } \\
\text { Device driver }\end{array}$ \\
& $\begin{array}{c}\text { Security in communication , Raw } \\
\text { driver and connection to TCP/IP }\end{array}$ \\
\hline RS 232 & $\begin{array}{c}\text { Serial communication standard, } \\
\text { Device 8251 }\end{array}$ & $\begin{array}{c}\text { Windows driver exists } \\
\text { PCIMCIA card }\end{array}$ & COM1 and COM2 available in PC \\
\hline RS 485 & Serial communication standard & $\begin{array}{c}\text { Windows driver exists } \\
\text { PCIMCIA card }\end{array}$ & \\
\hline Radio & $\begin{array}{c}\text { Device, like wireless LAN NIC } \\
\text { Broad cast }\end{array}$ & $\begin{array}{c}\text { Drivers may be } \\
\text { available }\end{array}$ & Present Wireless LAN Driver \\
\hline COM1, COM2 & $\begin{array}{c}\text { Existing PC Serial port } \\
\text { Serial devices can be used in } \\
\text { PC }\end{array}$ & & \\
\hline
\end{tabular}

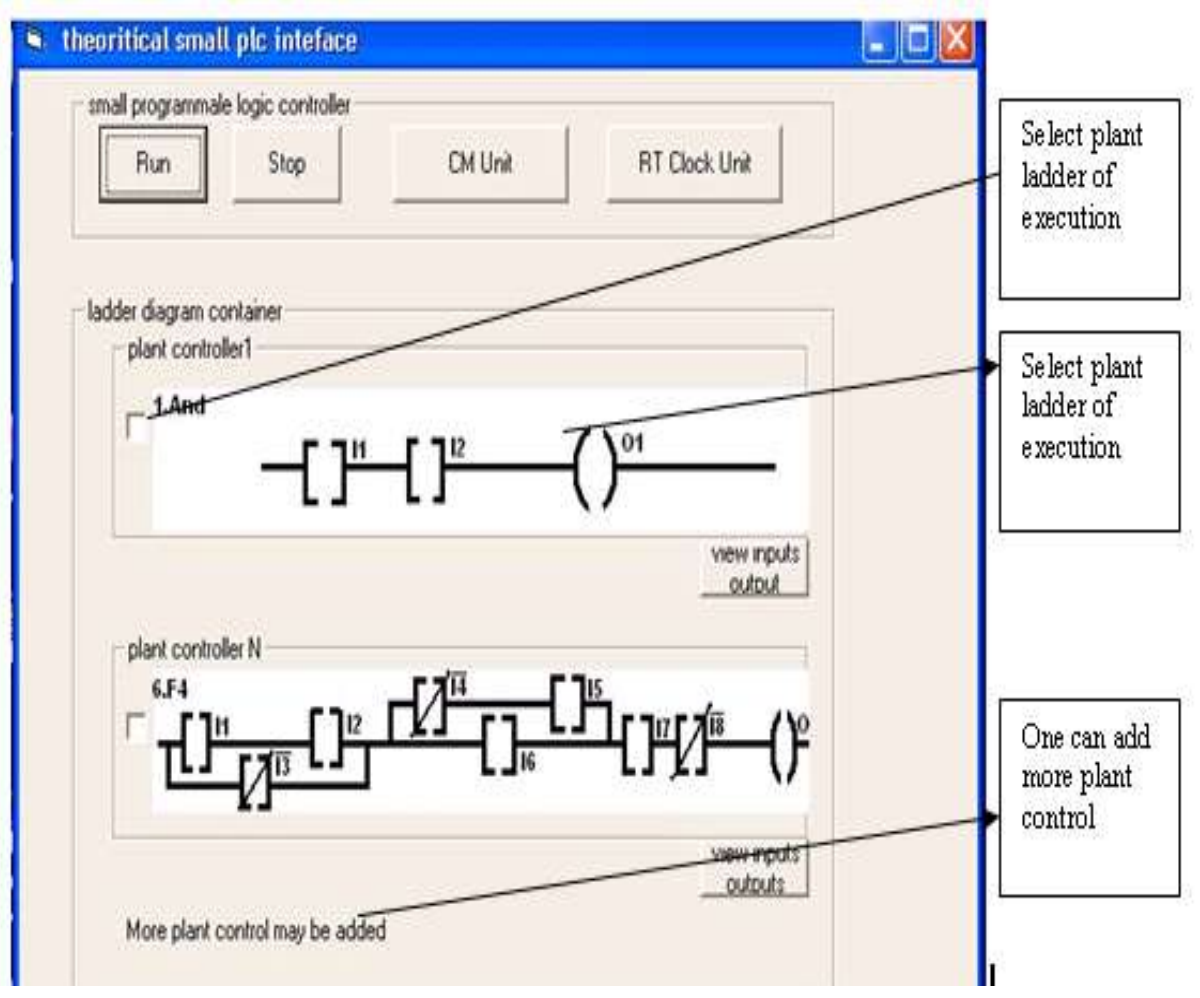

Figure 2. Theoretical Interface GUI

The command button "Run" is for running plant control selected and "Stop" stops. The command button "CM Unit" is meant for pop up interface for communication management interfacing plant and computer side PLC interface. The command button "RT Clock Unit" is meant for real time clock and timer management for this PLC [1]. During execution one can inspect inputs and outputs of the plant in real time logic by pressing "view inputs outputs". This small size interface may not be useful for large number of inputs and outputs in ladder of plant control.
Further integration to this theoretical interface in report generation and repository in terms of cheap available facility like Microsoft Excel (further MS Word, may be in CAD part).

\section{FUTURE WORK}

- CAD, A visual tool for arranging plant control diagrams, communication control, compiling and making a front end. 
- Hardware interface with real plant control. Commercial PLC interface need to be studied and front end communication module need to be standardized and portable communication interface module need to be made.

- Installing the output function code in the visual tool.

- Universal make to run in all platform and operating system in all networks.

- Use and up gradation as Education Technology Kit

- Simplest possible lab illustration and complete and incomplete logic.

- Time management, internet time, time.windows.com, time related API in windows.

- Robustness and reliability for all operating system and desktop computer.

- Ethernet compatibility.

- Programming model following IEC 61131-3.

\section{CONCLUSION}

In continuation of Software Engineering Research for Programmable Logic Controller, the work presented in this paper is sufficiently a primary step. The practical aspects of this work is done at Electrical Engineering Department, Veera
Surendra Sai University of Technology ( www.vssut.ac.in ), Orissa, India ; in under graduate project work and evaluated by experts well worthy. The work for a demo prototype is under progress.

\section{REFERENCES}

[1] A low cost programmable logic control (PLC) trainer for use in a university agricultural electricity course. Journal of Agriculture Technology, Management and Education. March 2006, Vol 21. By Aaron Dickinson, Ronal M, Donald M Johnson.

[2] Development of Object Oriented Modeling Tool for the design of Industrial Control logic . Kwan Hee Han; Jun Woo Park; Software Engineering Research, Management \& Applications, 2007. SERA 2007. 5th ACIS International Conference on 20-22 Aug. 2007 Page(s):353 358

[3] IEE Colloquium on advances in Software Engineering for PLC (Programmable Logic Controller ) Systems'. Advances in Software Engineering for PLC. 14 Oct 1993

[4] IUT X 200 to 215 recommendations on Open System Interconnection.

[5] A low cost programmable logic control (PLC) Trainer for Use in a Agricultural Electricity Course. Journal of Agricultural Technolgy, management and education. Maech 2006, Vol 21.

[6] IEC 61131-3

\section{AUTHORS PROFILE}

The author, B.K.Rana is a postgrduate in Electrical Engg from Indian Institute of Science, Bangalore, India in 1991. Subsequently worked in hardware and software in national and multinational companies. Presently a faculty in Electrical Engineering, Veer Surendra Sai University of Technology, Sambalpur, India and reseach in Industrial automation, Electrical Engineering software etc. are the fields of work. 